\title{
LA SISTEMÁTICA PROCESAL PENAL ACUSATORIA ES UN TODO Y NO UNA FRACCIÓN
}

Juan Guillermo Jaramillo Díaz
Magistrado Sala Penal Tribunal Superior de Medellín

Hasta sólo después de cuiminada la ll guerra mundial, la humanidad entendió dos connotadas afirmaciones: 'todo régimen político determina la manera de ser de la estructura de juzgamiento', la primera; y 'el derecho procesal es el derecho constitucional aplicado', la segunda.

Eso explica además el auge de la escuela exegética antes de aquél momento histórico ${ }^{3}$ (época de optimismo normativo), y su feliz y radical desaparición luego (época de pesimismo normativo). Durante aquel primer período, el DERECHO se sustentó en la LEY. Luego, con el surgimiento del constitucionalismo contemporáneo, la sustentación del derecho se logra ya en la NORMA, el HECHO y el VALOR ${ }^{4}$.

Debo aceptar que ese trascendental cambio se cumplió en Colombia sólo a partir de 1991, con la constitución política de la época. Cumple además identificar que ella es ideológicamente 'liberal' y ahí precisamente comienza a fundarse política y filosóficamente la SISTEMÁTICA ACUSATORIA ${ }^{5}$. Ese soporte se completa con la identificación de otros elementos tales como que Colombia es un Estado Constitucional de Derecho; es un Estado Social; ostenta un régimen republicano y democrático.

Sin duda, pues, en Colombia el derecho está constitucionalizado. Además, el régimen político allí trazado, trasciende y determina la manera de ser de la estructura de juzgamiento. Dicho de otra manera: si la ley 906 de 2004 ha implementado la sistemática procesal penal mixta con tendencia acusatoria, es porque la Constitución Política de 1991 así lo impone. Al fin y al cabo, la ley tiene que obedecer a la Constitución. Dos cuestiones serias se desprenden de lo anterior: 1 De ahí que la Roma Republicana determinó para la humanidad el nacimiento de la estructura acusatoria pura y luego la Roma mperial el surgimiento de la sistem

2 Tomás Santiago Vives Antón

3 El legislador es sabio; la ley es la expresión de la voluntad de la colectividad; la ley es clara y no se interpreta; el juez es la boca de la ley; la sentencia es un silogismo jurídico.

4 El legislador no es sabio; la ley no es la expresión de la voluntad de la colectividad; la ley hay que interpretarla; el juez es expresión de racionalidad; la sentencia es la norma jurídica individualizada.

5 La SOBERANÍA reside en la nación (Constitución Nacional de 1886). La SOBERANíA reside en el 'pueblo' (Constitución Política de 1991) 
1.- Para indagar por la naturaleza de una institución, el sendero no es la ley $y^{5}$ La fuente está inexorablemente en la Constitución. Por cierto que la jurisprudencia y la doctrina, en actitud de construcción, claro está, tienen por seguridad jurídica que hacer este recorrido.

2.- Como el legislador no es sabio, y el nuestro además es necio y altamente inconsulto, es necesario 'corregirlo' con miras a hacer realidad aquello de que una institución no es tanto lo que de ella diga la ley, sino su sustento constitucional. De ahí que, por ejemplo, ni la querella ni la petición especial son condiciones de procesabilidad (así lo dice la ley y lo reitera gran parte de la jurisprudencia y la doctrina) sino de procedibilidad (así debe entenderse constitucionalmente). De igual forma, el proceso jurisdiccional no se inicia como erradamente lo plantea el legislador en el artículo 126 de la ley 906 de $2004^{7}$.

La sistemática procesal penal mixta acusatoria está sustentada y ordenada en la Constitución Política de 1991 para la ACTUACIÓN, y no solamente para el proceso. De lo contrario, habría sido sin duda un avance a medias.

Los mojones político-filosóficos consignados en la Constitución iluminan y son directrices a la INDAGACIÓN, a la INVESTIGACIÓN, al PROCESO JURISDICCIONAL y a la EJECUCIÓN de la sentencia ejecutable. De tal suerte que si la implementada sistemática procesal mixta acusatoria se proyecta en estructura de AUDIENCIAS y utiliza el método de la ORALIDAD ${ }^{8}$, lo uno y lo otro han de aplicarse sin excepción posible a toda la actuación.

6 Colombia no es un Estado de derecho. Colombia es un Estado Constitucional de Derecho; cfr. C-336 de 2007.

7 Jaime Guasp Delgado, el padre de la pretensión, enseña que ésta determina la iniciación del proceso, lo connota y

8 La mixta inquisitoria utiliza la estructura longitudinal de actos y el método de la escritura.
Los órganos de investigación y las partes, de acuerdo con el momento, hacen las postulaciones en la audiencia correspondiente. Igual el condenado y su defensor. La decisión se pronuncia por el juez en la respectiva audiencia.

Si la ley 906 de 2004, en obedecimiento a la Constitución Política de 1991, con el ajuste hecho a través del acto legislativo 03 de 2002, implementó la sistemática procesal acusatoria, y aquella ley regula igualmente el momento postprocesal de la ejecución, ¿cómo no aceptar que este momento ha de gobernarse de la manera prevista para la investigación y el proceso jurisdiccional?

El código de procedimiento civil, que incluso hoy quiere oxigenarse del método de la oralidad característico de la expresión penal del proceso, no prevé normas inherentes a la ejecución de una sentencia que sean compatibies con la naturaleza de la penal. Un desalojo; un remate; el cumplimiento de un contrato, en fin, el reconocimiento de una paternidad, ¿qué tendrán que ver con la ejecución de la sentencia penal ejecutable?

La improvisación en la materialización de esa novísima sistemática acusatoria, e incluso la irresponsable pobreza en la dotación que ella requiere, pueden ser argumentos de INEFICACIA. Trátese entonces el tema como tal', con hombría de bien, pero para maquillar esa odiosa irregularidad no se diga que la sistemática procesal mixta acusatoria no es un todo y que se puede en consecuencia tratar de manera fraccionada.

El tema de las remisiones, el de la necesidad de construcción de más salas de audiencia y su adecuada dotación, pero amás la vergonzosa excusa de que el sistema implica más trabajo.
Nelson Saray Botero

Magistrado Sala Penal

Tribunal Superior del Distrito Judicial de Medellín

Es pertinente complementar el estudio sobre el tema de la actuación que se surte ante los Jueces de Ejecución de Penas en trámite de impugnaciones de procesos terminados en vigencia de la Ley 906 de 2004.

Primero: cuando se plantea la remisión a las normas civiles, es porque la misma ley lo permite para llenar los vacíos; $y$, por supuesto, como es apenas obvio, la remisión se hace a un tema concreto y específico para llenar el vacío y no a una remisión general y abstracta.

Así pues, las normas que se pueden aplicar son los artículos pertinentes del título de los "recursos" (artículos 348 y ss del CPC, modificados por el Decreto 2282 de 1989).

Segundo: esa remisión a la legislación civil se ha cumplido pacíficamente en tema como el desistimiento del recurso de apelación no expresamente consagrado en la Ley 906 de 2004 como sí se hizo para el desistimiento de la casación y la revisión (art. 199 Ley 906 de 2004).

De no actuarse de tal jaez, no se ve cómo es que se acepta el desistimiento de apelación en el sistema acusatorio penal cuando no está expresamente consagrado.

Tercero: igual sucede con el trámite del recurso de reposición y en subsidio el de apelación, no consagrado en la Ley 906 de 2004, pero que se ha admitido por remisión al inciso $2^{\circ}$ del art. 352 del CPC, modificado por el art. 36 Decreto 794 de 2003.

En efecto, sobre el particular dijo la Corte Suprema de Justicia en sede de tutela:

2.2. En materias no reguladas expresamente en ese Estatuto, se dice en su artículo 25, se aplican las normas del Código de Procedimiento Civil. Consiguientemente, de la misma manera como en consonancia con esa disposición cabe concluir que hay lugar al recurso de queja en el proceso oral cuando se nieguen los recursos de apelación o casación, se sigue que es pertinente interponer directamente el recurso de apelación o en subsidio del de reposición -ante el fracaso de éste-, acorde con el artículo 352 del Código de Procedimiento Civil, el cual establece que si la decisión se dicta en audiencia la apelación deberá proponerse inmediatamente de forma verbal, que el Juez la resolverá allí mismo y que esa impugnación se podrá interponer directamente "o en subsidio de la reposición". 
2.3. Impedir la posibilidad de utilización de los recursos ordinarios contra una decisión que los tolere desconoce la naturaleza de un proceso regido por la oralidad, en el que el funcionario judicial permanentemente decide y las partes, como es propio de un debate, pueden inmediatamente pedir que se reconsidere $y$ el Juez corregir un error que se le hace ver o persistir en su mandato. Si así es como suceden las cosas cuando existe controversia, no puede privarse al proceso de un instrumento de discusión como lo es el recurso de reposición que básicamente tiene como función impedir que el caso vaya a superior cuando es posible superar alguna diferencia en el mismo instante en el que ella se presenta, con los efectos protectores propios del principio de pronta y cumplida justicia.

Cuarto: el Sistema Acusatorio Penal no puede tomarse en su más excelsa y acabada teoría, pues el legislador patrio tiene libertad de configuración en tema legisferante siempre y cuando respete los valores, normas y principios de la Carta, como lo ha reconocido la Corte Constitucional en múltiples providencias de constitucionalidad.

\section{Así por ejemplo,}

(i) El recurso de apelación de la sentencia absolutoria, en un sistema puro acusatorio, no está permitido; sin embargo, nuestro legislador consagró expresamente esa posibilidad para el Fiscal, el Ministerio Público y el apoderado de la víctima (art. 177-1 $1^{\circ}$ Ley 906 de 2004, modificado por el art. 13 Ley 1142 de 2007, declarado cado por el art. 13 Ley 1142 de 2007, declarado
exequible por la Corte Constitucional mediante sentencia C-047 de 2006).

(ii) En ningún sistema acusatorio se presenta la intervención del Ministerio Público, y en otros, ni siquiera de las víctimas. Precisamente, conni siquiera de las víctimas. Precisamente, con-
sultando los valores y principios constituciona-

1 CSJ. Sala Penal, Sentencia de Tutela, Rad. 28.68 de 12 de diciembre de 2006. les el legislador reglamentó la intervención de las víctimas en el SAP como interviniente especial que actúa a través del Fiscal del proceso (C-209 de 2007; C-210 de 2007; C-343 de 2007; C-516 de 2007, entre otras).

Quinto: por esa potestad o libertad de configuración del legislador fue que no consagró las audiencias orales en trámites ante los Jueces de Ejecución de Penas y Medidas de Seguridad.

Nuestra tradición jurídica ha permitido definir esa fase o etapa como penal-administrativa.

Ese régimen tiene una regulación administrativa. Es así como, por ejemplo, el trabajo como forma de redención de pena está regulado en la Ley 65 de 1993 y además en resoluciones y acuerdos del INPEC, así: Ley 65 1993, arts. 10, 80, 142 al 145. Acuerdo 011 de 1995 Reglamento General para internos, Arts. 58 al 66; Acuerdo 010 de julio 01 de 2004 Reglamento General para el manejo de recursos propios del INPEC, generados en Establecimientos de Reclusión; Res. 6091 de 26 de julio de 2007 por el que se crea el programa general SOMA (Salud Ocupacional y Medio Ambiente) y deroga la Res. 0236 de enero 9 de 2006; Res. 7302 noviembre 23 de 2005, sobre pautas para la atención Integraly el Tratamiento Penitenciario; Res. 2392 mayo 3 de 2006 sobre Actividades válidas para redención de pena; Res. 2521, mayo 10 de 2006 sobre Aprobación metodología P.A.S.O; Circular 032 de 4 julio de 2006 sobre Asignación máxima de cubajo la modalidad de administración directa.

El Juez de Ejecución de Penas cumple su función en coordinación con las autoridades carcelarias ( $\mathrm{T}$ 718 de 1999; C-312 de 2002: CSJ. Sala Penal. Auto de 4 febrero de 2004, Rad. 7.026).

Estas son las aclaraciones que dejo a consideración de los distinguidos colegas.

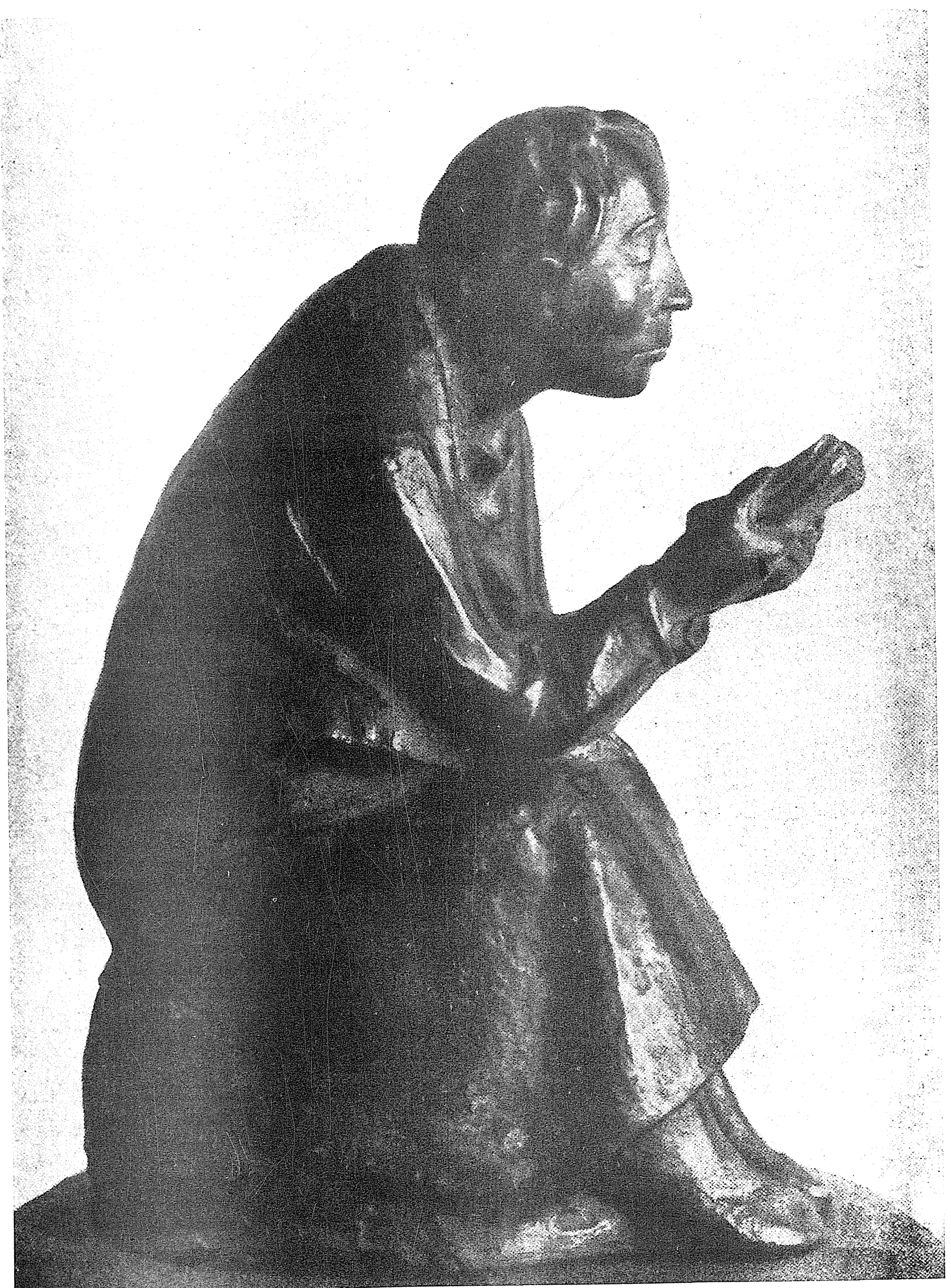

